International Journal of Social Science And Human Research

ISSN(print): 2644-0679, ISSN(online): 2644-0695

Volume 04 Issue 05 May 2021

DOI: 10.47191/ijsshr/v4-i5-04, Impact factor-5.586

Page No : 885-890

\title{
The Relationship between Organizational Capabilities and Strategic Management and Strategic Competitive Advantage of Employees of Computer School Staff in the Ghaemshahr City
}

\author{
Marzieh Bohloli Oskoei \\ Faculty Of Management Islamic Azad University Sari Iran
}

\begin{abstract}
This study aimed to investigate the relationship between organizational capabilities and strategic management, and the strategic competitive advantage of Ghaemshahr computer school employees. This research was descriptive of correlation type. The statistical population consisted of 100 employees of Ghaemshahr computer school in 2017-2018. A sample size of 80 people was selected by straddle random sampling based on gender. Data measurement tools included standard questionnaires of organizational capabilities of Jamshidi et al. (2014), Edward et al.'s human resources strategy (2006) and strategic competitive advantage of resident and Ramadan (2011). Experts confirmed the validity of the questionnaires, including supervisors, and by calculating Cronbach's alpha, the reliability of organizational capabilities questionnaires was 0.92 , strategic management equal to 0.89 strategic competitive advantage was calculated $0.87 \%$, which showed that the questionnaires had relatively high reliability. The data analysis method used descriptive statistics methods (calculation of frequency, percentages and standard deviation) and inferential statistics (Kolmogrov Smirnov test and Pearson and Spearman correlation coefficient test) through the SPSS 22 software program. The results showed a relationship between organizational capabilities and strategic management and the strategic competitive advantage of Ghaemshahr computer school employees. It also showed an association between organizational capabilities variables with strategic management and competitive advantage.
\end{abstract}

KEYWORDS: Organizational capabilities, Strategic management, Strategic competitive advantage, Employees.

\section{INTRODUCTION}

Employees play a crucial role in organizational performance, and no organizational capability is created without appropriate human infrastructure. Therefore, the organization's ability to manage human resources is essential for forming other capabilities and its competitive advantages. It is critical that it can make the human resources unit a strategic partner of the organization's business. However, it seems that there is a problem in the way of participation of these units in developing organizational capabilities. On the one hand, the CEOs of organizations complain that the human resources unit is "not a strategic business partner".

On the other hand, HR units complain that "they don't have seats on the decision table" (Sabet, 2014). In management research, organizational capabilities are defined as the ability to perform basic functional activities of the company, such as logistics and marketing. Researchers have found that capability can be identified using a standard functional classification of the company's activities (Lu et al., 2012). ). Nevertheless, organizational capabilities in a historical and francelli course are shaped on the competencies of its employees, especially leaders who have the power and authority to transfer their competencies to the organization. Nevertheless, organizational capabilities in a historical and francelli course are formed on the competencies of its employees, especially leaders who have the power and authority to transfer their competencies to the organization (Hashemi, 2014). Strategic management is more than just developing a strategic plan that includes pre-planning and strategic planning processes. Strategic management is the development and implementation of strategic planning and evaluation of results. It is related to the completion of the program and communication with all employees. Performance is related to allocating resources to the project, operating it and managing the project's activities. Measurement and evaluation include the follow-up of the implementation of the projects and something beyond that. Assessment and evaluation mean how the organization evaluates the results of the changes and uses the information obtained to update its plans. Using strategic management of the organization in a better way will understand its goals and vision. By updating the strategic plan, strategic managers better expand their programs, implement changes, and measure organization performance (Olad et al., 2011). In the new era, organizations have taken virtual and electronic modes of products, relationships and activities, and in general, their business has become virtual and electronic. Changes have become so severe that it minimizes the lifespan of technologies and products. Creating and maintaining a stable competitive advantage relying 


\section{The Relationship Between Organizational Capabilities and Strategic Management and Strategic Competitive Advantage of Employees of Computer School Staff in the Ghaemshahr City}

on traditional and old capabilities and competencies is not enough for the thriving presence of the organization in the environment and competitive markets. This requires new measures and approach to unique merits (Arefnejad et al., 2012).

Competitive advantage occurs when a company in an indicator or combination of indicators reaches developments and capabilities superior to competitors. Such as access to natural resources, or highly specialized human resources, industrial or information technologies, etc., competitive advantage, the increasing attractiveness of the company's offers in terms of customers compared to competitors. Competitive advantage is the distinction in features or dimensions that enables it to provide better services to customers than competitors, in general, the competitive advantage is the value that the organization offers to its customers so that at that time, this value is not provided by potential and actual competitors (Rastegar et Hemati, 2016). Abbaspour and Sabhani (2015) conducted research titled the role of strategic management in creating competitive advantage of organizations. The results showed that the human resources strategy promotes the company's strategy. Unique talents of employees such as superior performance, productivity, flexibility, creativity and the ability to provide a high level of independent services to customers are among the methods that employees can play a crucial role in creating a competitive position.

Zabihi and Nikpour (2014) conducted research titled "Strategic Management" in improving human resources performance. The results showed that performance management is one of the special topics of strategic human resource management and is a suitable tool for enhancing the performance of employees and organizations. Suppose performance management is designed and implemented in the organization with its requirements and prerequisites. In that case, it can identify some of the problems and problems of the organization and provide practical solutions to solve them. Performance management has a comprehensive approach to the performance of individuals and organizations and creates synergies between individual and organizational performance with specific mechanisms. Employees are the foundation of the company's success in gaining competitive advantage and creating added value. They should be treated as an essential strategic resource, so training, motivation, reward, resilience, teamwork and stable relationships ensure achievement of the company's strategies to their goals and improve performance. Nayebzadeh et al. (2013) conducted research entitled "Relationships between Strategic Trends, Organizational Capabilities and Performance" according to the role of changes in management accounting and control systems. The results showed that strategic trends significantly affect organizational capabilities and affect organizational performance through organizational capabilities and changes in management control and accounting systems.

Finally, this research can be exploitable and valuable for managers of manufacturing companies and researchers and researchers based on the obtained results, including providing strategies to improve organizational performance in management accounting. Esmailpour et al. (2012) conducted research entitled Information Systems and Competitive Advantage: An Approach Based on Organizational Capabilities. The results showed that information systems might play an essential role in empowering organizations to develop these organizational capabilities and create a competitive advantage. Mehmut et al. (2017) conducted a study entitled The Relationship between Strategic Abilities and Competitive Performance: The Codified Role of Internal Cooperation. The results showed that marketing capabilities, market-related capabilities, IT capabilities, and management capabilities as dimensions of strategic capabilities positively affect competitive performance. Besides, internal cooperation is the only relationship between management capabilities and competitive performance. Theoretical and practical concepts are discussed.

According to Al-Naabi et al. (2012), they conducted research entitled The effect of planning the company's resources on organizational capabilities and performance of the company. The results showed that the implementation of resource planning encourages and supports the research strategy, supports cost control, and supports new products and their introduction. Kumar et al. (2010) conducted research entitled Market Impact Centered as a source for gaining competitive advantage in organizations. The results showed that companies that were more focused on market-oriented activities had better performance and competitive advantage than other companies. Considering the importance of investigating the relationship between organizational capabilities with strategic management and strategic competitive advantage of employees of Ghaemshahr computer school, and considering that no research has been conducted in Ghaemshahr computer school in this regard, it is necessary to conduct this research, one of the instantaneous results of this research is to identify the relationship between organizational capabilities and strategic management and strategic competitive advantage of employees of Ghaemshahr computer school.

The future results of the research, providing strategies and guidelines to the authorities and stakeholders to strengthen and develop the relationship between organizational capabilities and strategic management and strategic competitive advantage of computer school staff and covering their weaknesses, can be mentioned. Therefore, this research can be applied to all employees and other enthusiasts in this field. According to the above, the present study seeks to answer whether there is a relationship between organizational capabilities and strategic management and strategic competitive advantage of computer school staff in Qaemshahr city?

In this regard, the hypotheses of the research are as follows.

Central hypothesis: There is a relationship between organizational capabilities and strategic management, and strategic competitive advantage in computer school staff of Ghaemshahr city.

Sub hypothesis 1: There is a relationship between high-rank capabilities and strategic management in computer school staff. 
The Relationship Between Organizational Capabilities and Strategic Management and Strategic Competitive
Advantage of Employees of Computer School Staff in the Ghaemshahr City

Sub hypothesis 2: There is a relationship between intermediate capabilities and strategic management in computer school staff.

Sub hypothesis 3: There is a relationship between low capabilities and strategic management in computer school staff.

Sub hypothesis 4: There is a relationship between high-rank capabilities and strategic competitive advantage in computer school staff.

Sub hypothesis 5: There is a relationship between intermediate capabilities and strategic competitive advantage in computer school staff.

Sub hypothesis 6: There is a relationship between low capabilities and strategic competitive advantage in computer school staff.

\section{RESEARCH METHODOLOGY}

In terms of applied purpose, the present study is a field data collection method and a survey in descriptive implementation. In this study, the statistical population consisted of 100 employees of Ghaemshahr Computer School in 2017-2018. According to the size of the society, using Krejcie and Morgan tables and a random stratified sampling method based on gender, 80 people were selected as the sample size.

The researcher used three standard questionnaires to use the research tool. First Organizational Capabilities Questionnaire: This questionnaire was designed by Jamshidi et al. in 2014 under three dimensions including 33 questions and had five necessary coefficients as very low (value 1), low (value 2), medium (value 3), high (value 4) and very high (value 5). Second Strategic Management Questionnaire: This questionnaire was constructed by Edward et al. in 2006. The questionnaire consisted of 27 questions as (A and B). A) Having four significant coefficients as too high (value 1), high (value 2), low (value 3), meagre (value 4), and b) has three essential coefficients as 1- not in our programs 2- possible concentration 3- is an essential future focus. Third Strategic Competitive Advantage Questionnaire: Moghimi and Ramadan designed this questionnaire in 2011, which includes 15 questions and five coefficients of importance very strongly agree (value 1), I agree (value 2), I do not entirely agree (value 3), I disagree (value 4), and I can't wholly agree very much (value 5). The reliability of the questionnaires in this study (organizational capabilities equal to 0.92 , strategic management equal to 0.89 strategic competitive advantage equal to $0.87 \mathrm{bps}$ ) was obtained. The descriptive section methods (calculation of frequency, percentages and standard deviation) and inferential part (Kolmogrov Smirnov test and Pearson and Spearman correlation coefficient test) were used by SPSS 22 software program to analyze the data.

\section{RESULTS}

\section{Data Description}

In the descriptive section, the results showed that the highest frequency was related to the female gender range $(61 \%)$, and the lowest frequency was related to male (39\%). The highest frequency was related to the age range of fewer than 30 years (39\%), and the lowest frequency was related to more than 45 years $(27 \%)$. The highest frequency was related to undergraduate study (43\%), and the lowest frequency was related to master's degree and higher $(26 \%)$.

\section{Normality of data}

To evaluate the normality of the variables in the study, Kolmogrov Smirnov was used, which the results showed that in highrank capabilities, medium capabilities and low capabilities of $\mathrm{Sig}=\alpha<=0.000$, then $\mathrm{H} 0$ (normality of research variables) is rejected and the parametric test of Spearman correlation coefficient is used. Also, in organizational capabilities, $0.05=\alpha>$ is $0.08=$ Sig., so H0 (normality of research variables) is not ruled out, and a nonparametric test of Pearson correlation coefficient is used.

Test assumptions

Central hypothesis: There is a relationship between organizational capabilities and strategic management, and strategic competitive advantage in computer school staff of Ghaemshahr city.

Table 1: A Correlation Study of the Relationship between Organizational Capabilities with Strategic Management and Strategic Competitive Advantage

\begin{tabular}{|c|c|c|c|}
\hline \multicolumn{2}{|l|}{ Statistical Indicators } & \multirow{2}{*}{ Variables } \\
\hline $\mathrm{n}$ & $\mathrm{r}$ & Sig. & Strategic Management \\
\hline 80 & 0.309 & 0.000 & $\begin{array}{l}\text { Strategic competitive } \\
\text { advantage }\end{array}$ \\
\hline 80 & 0.328 & 0.003 & \\
\hline
\end{tabular}



The Relationship Between Organizational Capabilities and Strategic Management and Strategic Competitive
Advantage of Employees of Computer School Staff in the Ghaemshahr City

The results of table (1) show that at the confidence level of $95 \%(\alpha=0.05)$, the data reject the zero hypothesis $\left(H_{-} 0\right)$ and confirm the research hypothesis $\left(\mathrm{H} \_1\right)$, why in strategic management $(0.05=\alpha>0.000=$ Sig. $)$ and in strategic competitive advantage $(0.05=\alpha$ $>0.003=$ Sig. $)$ it is. Therefore, it can be claimed that there is a relationship between organizational capabilities and strategic management and strategic competitive advantage in computer school staff of Ghaemshahr city.

Sub hypothesis 1: There is a relationship between high-rank capabilities and strategic management in computer school staff.

Table 2: Correlation study of the relationship between high-rank capabilities and strategic management in employees

\begin{tabular}{|l|l|l|}
\hline \multicolumn{2}{|l|}{ High-rank capabilities } & \multirow{2}{*}{ Variables } \\
\hline Computational values & Statistical Indicators & \multirow{2}{*}{ Strategic Management } \\
\hline $\mathrm{n}$ & 80 & \\
\hline $\mathrm{r}$ & 0.438 & \\
\hline Sig. & 0.000 & \\
\hline
\end{tabular}

The results of table (2) show that at the confidence level of $95 \%(\alpha=0.05)$, the data reject the zero hypothesis $\left(\mathrm{H} \_0\right)$ and confirm the theory of the research $\left(\mathrm{H}_{-} 1\right)$ because it is $(0.05=\alpha>0.000=$ Sig.). Therefore, it can be claimed that there is a relationship between high-rank capabilities and strategic management in employees.

Sub hypothesis 2: There is a relationship between intermediate capabilities and strategic management in computer school staff.

Table 3: Correlation study of the relationship between average capabilities and strategic management in employees

\begin{tabular}{|l|l|l|}
\hline \multicolumn{2}{|l|}{ Medium-sized functionality } & \multirow{2}{*}{ Variables } \\
\hline Computational values & Statistical Indicators & \\
\hline $\mathrm{n}$ & 80 & \multirow{2}{*}{ Strategic Management } \\
\hline $\mathrm{r}$ & 0.401 & \\
\hline Sig. & 0.000 & \\
\hline
\end{tabular}

The results of table (3) show that at the confidence level of $95 \%(\alpha=0.05)$, the data reject the zero hypothesis $\left(\mathrm{H}_{-} 0\right)$ and confirm the theory of the research (H_1) because it is $(0.05=\alpha>0.000=\mathrm{Sig}$.). Therefore, it can be claimed that there is a relationship between medium capabilities and strategic management in computer school staff.

Sub hypothesis 3: There is a relationship between low capabilities and strategic management in computer school staff.

Table 4: Correlation study of the relationship between low capabilities and strategic management in employees

\begin{tabular}{|l|l|l|}
\hline \multicolumn{2}{|l|}{ Low functionality } & Variables \\
\hline Computational values & Statistical Indicators & \\
\hline $\mathrm{n}$ & 80 & \multirow{2}{*}{ Strategic Management } \\
\hline $\mathrm{r}$ & 0.401 & \\
\hline Sig. & 0.000 & \\
\hline
\end{tabular}

The results of table (4) show that at the confidence level of $95 \%(\alpha=0.05)$, the data reject the research hypothesis $\left(H_{-} 1\right)$ and confirm the zero ideas ( $\left.H_{-} 0\right)$ because it is $(0.05=\alpha<0.349=$ Sig.). Therefore, it can be claimed that there is no relationship between low capabilities and strategic management in computer school staff.

Sub hypothesis 4: There is a relationship between high-rank capabilities and strategic competitive advantage in computer school staff. 
The Relationship Between Organizational Capabilities and Strategic Management and Strategic Competitive Advantage of Employees of Computer School Staff in the Ghaemshahr City

Table 5: Correlation study of the relationship between high-rank capabilities and strategic competitive advantage in employees

\begin{tabular}{|l|c|c|}
\hline \multicolumn{2}{|l|}{ High-rank capabilities } & \multirow{2}{*}{ Variables } \\
\hline Computational values & Statistical Indicators & \\
\hline $\mathrm{n}$ & 80 & \multirow{2}{*}{ Strategic Management } \\
\hline $\mathrm{r}$ & 0.491 & \\
\hline Sig. & 0.000 & \\
\hline
\end{tabular}

The results of table (5) show that at the confidence level of $95 \%(\alpha=0.05)$, the data reject the zero hypothesis $\left(\mathrm{H} \_0\right)$ and confirm the theory of the research (H_1) because it is $(0.05=\alpha>0.000=$ Sig. $)$. Therefore, it can be claimed that there is a relationship between high-rank capabilities and strategic competitive advantage in computer school staff.

Sub hypothesis 5: There is a relationship between intermediate capabilities and strategic competitive advantage in computer school staff.

Table 6: Correlation study of the relationship between medium capabilities and strategic competitive advantage in employees

\begin{tabular}{|l|c|c|}
\hline \multicolumn{2}{|l|}{ Medium capabilities } & \multirow{2}{*}{ Variables } \\
\hline Computational values & Statistical Indicators & \multirow{2}{*}{ Strategic Management } \\
\hline $\mathrm{n}$ & 80 & \\
\hline $\mathrm{r}$ & 0.498 & \\
\hline Sig. & 0.000 & \\
\hline
\end{tabular}

The results of Table $(6)$ show that at $95 \%$ confidence level $(\alpha=0.05)$, the data reject the null hypothesis $\left(\mathrm{H} \_0\right)$ and confirm the research hypothesis $\left(H_{-} 1\right)$, because $(\alpha=0.05>\operatorname{Sig}=0.000$.) is. Therefore, it can be argued that there is a relationship between mediocre capabilities and strategic competitive advantage in computer school staff.

Sub-Hypothesis 6: There is a relationship between low capabilities and strategic competitive advantage in computer school staff.

Table 7: Investigating the correlation between the relationship between low capabilities and strategic competitive advantage in employees

\begin{tabular}{|l|l|l|}
\hline \multicolumn{2}{|l|}{ Low functionality } & \multirow{2}{*}{ Variables } \\
\hline Computational values & Statistical Indicators & \\
\hline $\mathrm{n}$ & 80 & \multirow{2}{*}{ Strategic Management } \\
\hline $\mathrm{r}$ & 0.059 & \\
\hline Sig. & 0.601 \\
\hline
\end{tabular}

The results of Table (7) show that at the 95\% confidence level $(\alpha=0.05)$, the data reject the research hypothesis (H_1) and confirm the null hypothesis $\left(\mathrm{H} \_0\right)$, because $(\alpha=0.05<0.601=$ Sig. $)$ is. Therefore, it can be argued that there is no relationship between low capabilities and strategic competitive advantage in computer school staff.

\section{DISCUSSION AND CONCLUSION}

In examining the central hypothesis, the findings showed a relationship between organizational capabilities with strategic management and strategic competitive advantage in the staff of Ghaemshahr computer school. The obtained results are in line with the results of Abbaspour and Sabhani (2015), Nayebzadeh et al. (2013), Ismailpour et al. (2012) and Mehmet et al. (2017). In 


\section{The Relationship Between Organizational Capabilities and Strategic Management and Strategic Competitive Advantage of Employees of Computer School Staff in the Ghaemshahr City}

examining Hypothesis 1, the findings showed a relationship between high-ranking capabilities and strategic management in employees. The obtained result is in line with the results of Zabihi and Nikpour (2014) researches. In examining Hypothesis 2, the findings showed a relationship between intermediate capabilities and strategic management in computer school staff. The obtained result is in line with the research of Nayebzadeh et al. (2013), Ismailpour et al. (2012) and Kumar et al. (2010). In examining Hypothesis 3, the findings showed no relationship between low capabilities and strategic management in computer school staff. The obtained results are in line with the results of the researches of Abbaspour and Sabhani (2015), Ismailpour et al. (2012), Mehmet et al. (2017), and Al-Nabi et al. (2012). In examining Hypothesis 4, the findings showed a relationship between high ranking capabilities and strategic competitive advantage in computer school staff. The obtained result is in line with the results of Zabihi and Nikpour (2014), Nayebzadeh et al. (2013) and Hasab Al-Nabi et al. (2012). In examining Hypothesis 5, the findings showed a relationship between average capabilities and strategic competitive advantage in computer school staff. The obtained result is in line with the results of research by Nayebzadeh et al. (2013), Ismailpour et al. (2012) and Kumar et al. (2010). In examining Hypothesis 6 , the findings showed no relationship between low capabilities and strategic competitive advantage in computer school staff. The obtained result is in line with the results of Abbaspour and Sabhani (2015), Nayebzadeh et al. (2013), Ismailpour et al. (2012) and Kumar et al. (2010).

\section{REFERENCE}

1) Ismailpour, Reza; King of Ethics, Ismail; Gholamin, Rahela. (2012). Information systems and competitive advantage: An approach based on organizational capabilities. Available at r.gholamin@yahoo.com

2) Olad, faith; Shaygan, Faith; Hashemi, Ismail (2011). Strategic management for senior managers. Available at www.hajarian.com

3) Sabet, Mohammad Javad (2014). The role of the human resources unit in the development of organizational capabilities. Industrial Management, Volume 25, Number 270, pp: 36-33.

4) Zabihi and Nikpour (2014). Processes and mechanisms for creating and maintaining a sustainable competitive advantage. Proceedings of the Second International Conference on Financial Services Marketing, Tehran: Publication.

5) Rastegar, Abbas Ali; Hemmati, Amin. (2016). Measuring the impact of competitive strategies on the performance of the organization. Fourth International Conference on Strategic Management, University of Tehran.

6) Arefnejad, Mohsen; Amirkhani, Taybeh; Subhanab, Mohammad (2012). Explaining the factors affecting the success of information systems: with emphasis on the role of organizational factors and organizational learning (in Isfahan Industries and Mines Organization). Information Technology Management, Volume 4, Number 13, pp: 114-89.

7) Abbaspour, Ehsan; Sabhani, Mehdi (2015). The role of strategic human resource management (SHRM) in creating a competitive advantage of organizations. Third International Conference on Science and Technology Research, available at http://scholar.conference.ac/index.php/download/file/task-sendlink/index.php?

8) Nayebzadeh, Shahnaz; Ashraf Ganjoui, Asma; Moinuddin, Mahmoud (2013). Investigating the relationships between strategic orientations, organizational capabilities and performance concerning the role of changes in management control and accounting systems. Journal of Management Health Research Accounting and Auditing Knowledge, Volume 2, Number 8, pp: 82-71.

9) Hashemi, Mohammad Mehdi (2014). Individual competencies and organizational capabilities. Tadbir, Vol. 25, No. 27, pp. $32-28$.

10) HassabElnaby, H. R.; Hwang, W.; Vonderembse, M.A. (2012). The impact of ERP implementation on organizational capabilities and firm performance. Benchmarking: An International Journal, Vol.19 No. 4/5, PP 618-633

11) Kumar, V.; Eli Jones, R.; Venkatesan, R; Leone, P. (2010). MARKET ORIENTATION A SOURCE OF SUSTAINABLE COMPETITIVE ADVANTAGE OR SIMPLY THE COST OF COMPETING. Journal of Marketing Article Postprint

12) Luo, J.; Fan, M.; Zhang, H. (2012). Information technology and organizational capabilities: A longitudinal study of the apparel industry. Decision Support Systems, 53, PP: 186-194

13) Mehmet, S.; Sibel, A.; Ümit, S.; Özlem, Y. U. (2017). The Relationship between Strategic Capabilities and Competitive Performance: The Moderating Role of Internal Cooperation. International Journal of Academic Research in Economics and Management Sciences, Vol. 6, No. 1, p: 2226-3624. 